\title{
ЕПІДЕМІОЛОГІЯ СИНДРОМУ ПОЛІКІСТОЗНИХ ЯЄЧНИКІВ, ЕНДОМЕТРІОЗУ ТА ЇХ КОМОРБІДНОГО ПЕРЕБІГУ
}

\section{Епідеміологія синдрому полікістозних яєчників,} ендометріозу та їх коморбідного перебігу

А. С. Хміль Досвальд, М. С. Хміль, С. В. Хміль

Тернопільський національний медичний університет імені І. Я. Горбачевського МОЗ України

Резюме. Синдром полікістозних яєчників (СПКЯ) $\epsilon$ найпоширенішим ендокринним розладом в осіб жіночої статі. Актуальність проблеми синдрому полікістозних яєчників, його коморбідного перебігу, вплив на фрертильність, тактика ведення таких пацієнтів продовжує зростає, все більша кількість наукових праць спрямована на вивчення даної патології.

Мета дослідження - проаналізувати літературні дані щодо поширеності синдрому полікістосних яєчників, ендометріозу та їх коморбідного перебігу і вплив на розвиток безпліддя.

Матеріали і методи. У дослідженні опрацьовано наукові публікації за останнє десятиліття, а також публікації з високою цитованістю, які доступні у мережі «Internet», ключовими словами були: «синдром полікістозних яєчників», «ендометріоз», «коморбідність», «безпліддя».

Результати. Безпліддя вражає 40 \% жінок із СПКЯ, що є найбільш поширеною причиною ановуляторного безпліддя. Приблизно 90-95 \% жінок з ановуляцією, які звертаються в клініку, мають СПКЯ. Ендометріоз $i$ СПКЯ супроводжуються зміною фрункціонування жіночої гіпоталамус-гіпофріз-гонади осі, але їх до цього часу не розглядають як патології, що пов'язані одна з одною. За даними наукових досліджень, СПкЯ та ендометріоз $є$ захворюваннями, які часто зустрічаються у жінок репродуктивного віку. Обидва негативно впливають на народжуваність. Brincat et al. повідомили, що $10 \%$ безплідної популяції мала ендометріоз і СПКЯ, що становить $48 \%$ усіх пацієнток із СПКЯ. Щоб покращити успіх індукції овуляції, McGovern et al. обговорили важливість скринінгу інших причин безпліддя у жінок із СПКЯ, в тому числі ендометріозу.

Висновки. Враховуючи високу поширеність синдрому полікістозних яєчників, ендометріозу, а також їх коморбідного перебігу, виникає необхідність розуміння механізмів розвитку безпліддя у таких пацієнток, що дозволить обґрунтувати тактику лікування безпліддя, спричиненого даними захворюваннями.

Ключові слова: синдром полікістозних яєчників; ендометріоз; безпліддя; поширеність.
Epidemiology of polycystic ovary syndrome, endometriosis and their comorbid course

A. S. Khmil Doswald, M. S. Khmil, S. V. Khmil

I. Horbachevsky Ternopil National Medical University

e-mail: hmil@tdmu.edu.ua

Summary. Polycystic ovary syndrome (PCOS) is the most common endocrine disorder in females. The urgency of the problem of polycystic ovary syndrome, its comorbid course, the impact on fertility, the tactics of such patients continues to grow, an increasing number of scientific papers aimed at studying this pathology

The aim of the study - to analyze the literature on the prevalence of polycystic ovary syndrome, endometriosis and their comorbid course and their impact on the development of infertility

Materials and Methods. The study examined scientific publications over the past decade, as well as highly cited publications available on the Internet, the key words were "polycystic ovary syndrome", "endometriosis", "comorbidity", "infertility".

Results. Infertility affects $40 \%$ of women with PCOS. PCOS is the most common cause of anovulatory infertility. Approximately 90-95\% of women with anovulation who go to the clinic have PCOS. Endometriosis and PCOS are accompanied by changes in the functioning of the female hypothalamic-pituitary-gonadal axis, but they are still not considered as pathologies related to each other. According to scientific studies, PCOS and endometriosis are diseases that are common in women of childbearing age. Both negatively affect fertility. Brincat and co-authors reported that $10 \%$ of the infertile population had endometriosis and PCOS, accounting for $48 \%$ of all PCOS patients. To improve the success of ovulation induction, McGovern and colleagues discussed the importance of screening for other causes of infertility in women with PCOS, including endometriosis.

Conclusions. Given the high prevalence of polycystic ovary syndrome, endometriosis, and their comorbid course, there is a need to understand the mechanisms of infertility in such patients, which will justify the tactics of treatment of infertility caused by these diseases.

Key words: polycystic ovary syndrome; endometriosis; infertility; prevalence. 


\section{встУп}

Синдром полікістозних яєчників (СПКЯ) є найпоширенішим ендокринним розладом в осіб жіночої статі [1-3]. СПКЯ є гетерогенним ендокринним захворюванням, що вражає жінок, які мають характерні ознаки кіст яєчників, ановуляції та ендокринних змін. За оцінками Всесвітньої організації охорони здоров'я (ВООЗ), понад 116 млн жінок (3,4 \%) хворіють на СПКЯ в усьому світі $[4,5]$. СПКЯ вражає жінок усіх рас і етнічних груп репродуктивного віку. В неуточнених групах населення поширеність СПкя становить 3-10\% [6, 7]. СПКЯ - це синдром, який найчастіше характеризується дисбалансом статевих гормонів [1]. Загальні симптоми включають нерегулярний менструальний цикл, полікістоз яєчників і гірсутизм [2]. Особливості синдрому також можуть включати безпліддя, інсулінорезистентність, порушення толерантності до глюкози (цукровий діабет 2 типу) та дисліпідемію через підвищені фрактори ризику [8]. Частота віддалених ускладнень, включаючи серцево-цереброваскулярні захворювання, артеріальну гіпертензію, порушення ліпідного обміну та рак ендометрія, у пацієнток із СПКЯ в 2-6 разів перевищує частоту в жінок без СПКЯ [9]. Етіологія СПКЯ повністю не вивчена і до кінця не дослідженими залишаються причини даного синдрому, хоча були ідентисіковані генетичний компонент та фрактори харчування/способу життя, такі, як інсулінорезистентність та ожиріння [10, 11]. Враховуючи вплив інсулінорезистентності та ожиріння на розвиток СПКЯ, це може бути пов'язано з різницею в поширеності між різними расами/етнічністю 3 більш високою частотою ожиріння та діабету. Через гетерогенну та багатофракторну природу симптомів СПКЯ бракує чіткого, узгодженого визначення та діагностичних критеріїв [10, 12]. Постановка діагнозу СПКЯ дозволяє пацієнтці знати про можливі проблеми з фертильністю, дисфуункціональну кровотечу, рак ендометрія, ожиріння, цукровий діабет, дисліпідемію, артеріальну гіпертензію та теоретично підвищений ризик серцево-судинних захворювань [11]. 3 огляду на те, що інсулінорезистентність сильно пов'язана з СПКЯ, ці особи потребують посиленого скринінгу і, ймовірно, матимуть кращі довгострокові результати при ранній корекції способу життя, а також при застосуванні препаратів, що сенсибілізують інсулін, таких як меторормін. Крім того, скринінг на гіперліпідемію може призвести до більш ранньої модифрікації способу життя, що ймовірно, може допомогти зменшити серцево-судинні наслідки.

Загалом, актуальність проблеми синдрому полікістозних яєчників, його коморбідного перебігу, вплив на фертильність, тактика ведення таких пацієнтів продовжує зростати, все більша кількість наукових праць спрямована на вивчення даної патології.
Метою дослідження було проаналізувати літературні дані щодо поширеності синдрому полікістосних яєчників, ендометріозу та їх коморбідного перебігу та їх вплив на розвиток безпліддя.

\section{МАТЕРІАЛИ I МЕТОДИ}

У дослідженні опрацьовано наукові публікації за останнє десятиліття, а також публікації із високою цитованістю, які доступні у мережі «Internet», ключовими словами були: «синдром полікістозних яєчників», «ендометріоз», «коморбідність», «безпліддя».

\section{РЕЗУЛЬТАТИ Й ОБГОВОРЕННЯ}

У сучасній літературі існує великий розрив між поширеністю СПКЯ, географрічними регіонами та расовими/етнічними фракторами [13]. Існує кілька досліджень, які вивчали конкретні субпопуляції. Ці дослідження, зазвичай, обмежені невеликими розмірами вибірки, упередженістю відбору та їх не можна порівняти з результатами інших досліджень через невідповідність діагностичним критеріям СПКЯ. щоб повністю зрозуміти складність і поширеність СПКЯ, необхідно оцінити поширеність у субпопуляціях [14]. Глобальна поширеність СПКЯ оцінюється в межах від 6 до 26 \% [15-17]. G. Bozdag et al. [18] провели систематичний огляд та метааналіз опублікованих досліджень, у яких повідомлялося про поширеність СПКЯ. Їхні результати показали, що глобальна поширеність СПКЯ коливається від 6 до 10 \% залежно від застосованих критеріїв. Подібні епідеміологічні дослідження прийшли до висновку, що поширеність СПКЯ за Роттердамськими критеріями приблизно вдвічі більша, ніж за критеріями Національного інституту здоров'я (NIH) $[2,19]$. У дослідницькому опитуванні Rao Manisha et al. щодо поширеності СПКЯ серед жінок виявили, що 28,5\% жінок мали офріційний діагноз СПкя. Однак ця поширеність може бути заниженою, оскільки майже половина $(40,5 \%)$ жінок, яким не був офріційно поставлений діагноз, мали симптоми, що відповідають Роттердамським діагностичним критеріям СПкЯ [19]. За даними Центрів з контролю та профрілактики захворювань, поширеність СпКЯ у Сполучених Штатах Америки становить від 6 до 12 \% [20]. За останні роки захворюваність на СПКЯ зросла, і 3 удосконаленням методів діагностики, рівня діагностики та лікування його поширеність може відповідно змінюватися [21].

Варіабельність оцінок поширеності СПКЯ може бути пов'язана з кількома фракторами. По-перше, залежно від місця збору даних у вибірковій сукупності може бути неоднорідність у расовому, етнічному та віковому розподілі. Ці змінні можуть впливати з часом на клінічну картину гіперандрогенії та зовнішній вигляд фолікулів яєчників за допомогою ультразвукового дослідження. Наприклад, іспаномовні жінки 
з СПКЯ часто мають більш високу поширеність гірсутизму, гіперандрогенії та гіперглікемії, порівняно 3 білими жінками, які не латиноамериканки, i, як правило, мають вищі показники метаболічного синдрому та гіпертриацилгліцеролемії, ніж неіспаномовні темношкірі жінки $[10,22]$. По-друге, біохімічні та ультразвукові тести для діагностики та виключення пов'язаних 3 ними розладів можуть бути логістично складними через причини, пов'язані з витратами, часом та персоналом. По-третє, зручна для дослідження вибірка може не відображати фрактичну поширеність серед населення [3]. Дослідження M. Gibson-Helm et al. показало, що більше однієї третини жінок із СПКЯ довелося чекати більше 2 років і відвідувати принаймні 3 різних медичних працівників, перш ніж їм був встановлений діагноз [23]. При цьому інформацію про СПКя та його відділені наслідки пацієнтки шукали з онлайн-ресурсів, де якість інфрормації різна. Загалом, існує очевидна потреба вивчити різні аспекти обізнаності та розуміння жінок СПКЯ, а також їхні джерела інформації.

Щодо етнічної відмінності у поширеності СПКЯ, Nidhiet et al. у 2011 р. провели проспективне дослідження за участю 460 дівчат 15-18 років із коледжу в Південній Індії та повідомили про рівень поширеності - 9,13 \% [24]. Дослідження 2017 р., проведене Gupta et al., показало рівень поширеності 8,2 \% [25] . Пізніше, протягом 2017 р., A. Choudhary et al. показали вищу поширеність у 41\% в 170 жінок із порушеннями менструального циклу за критеріями NIH. Метааналіз, проведений Ding et al. y 2017 р., розглянув поширеність СПКЯ серед різних етнічних груп і зробив висновок, що жінки європеоїдної раси менш схильні до розвитку СПКЯ порівняно 3 населенням Близького Сходу та небілими жінками [26]. Відповідно, поширеність СПКЯ різна в різних країнах світу. Іран, Китай та США повідомили про поширеність 3; 2,2 та 4,7 \% відповідно. Бразилія, Пекін, Шрі-Ланка, Палестина, Греція, Великобританія та Іспанія виявили рівень поширеності в діапазоні 5-10 \%. Данія, Туреччина та Австралія повідомили про більш високий діапазон поширеності (15-20 \%). У 2018 p.Wolf et al. також повідомили про поширеність СПкЯ в Мексиці, що складає 13 \% [10]. У 2019 р. Ganie et al. зробили висновок, що поширеність СПКЯ в Індії становить від 3,7 до 22,5 \% залежно від досліджуваної популяції та критеріїв, які використовуються для діагностики [27]. Результати дослідження загальної поширеності СПКЯ в Китаї показали, що вона становить 10,01\%, що вище, ніж результати, отримані R. Li et al. [28] в епідеміологічному обстеженні жіночого СПКЯ. Проте поширеність СПКЯ в цьому дослідженні була нижчою, ніж у жінок Близького Сходу (16 \%) [26, 29], що може бути пов'язано з расою, регіоном, економічним та культурним рівнем, а також покращенням знань та діагностики СПкЯ. ще однією особливості поширеності сПкя серед жінок є їх вік. Результати аналізу за віком дослідженні Qiao Wu et al. 9] показали, що рівень поширеності становив 10,26 \% для жінок у віці від 10 до 20 років, 17,23 \% для жінок у віці від 21 до 30 років і 9,13 \% для жінок у віці від 31 до 40 років. У віці понад 40 років поширеність СПкЯ у жінок становила 2,22 \%. Цей результат показує, що поширеність СПКЯ значно зменшилася з віком від 21 до 30 років, що свідчить про те, що вік може бути пов'язаний із СПКЯ. Причина може полягати в сприятливому періоді для жінок дітородного віку від 20 до 29 років, жіноча репродуктивна ендокринна фрункція досягає свого піку, ендокринна функція яєчників активна, а ендокринна фрункція яєчників жінок переходить у стан поступового зниження до 40 років [7]. Поширеність СПКЯ, яка тісно пов'язана з ендокринною фрункцією, також зменшується з поступовим ослабленням ендокринної функції яєчників.

Безпліддя вражає 40 \% жінок із СПкя [30], є найбільш поширеною причиною ановуляторного безпліддя. Приблизно 90-95 \% жінок 3 ановуляцією, які звертаються в клініку, мають СПкЯ. У жінок із СПкЯ нормальна кількість примордіальних фолікулів, а первинні та вторинні фролікули значно збільшені. Однак через порушення фракторів, що беруть участь у нормальному розвитку фролікулів, ріст їх припиняється, коли вони досягають діаметра 4-8 мм. Оскільки домінантний фролікул не розвивається, овуляція не настає [31]. Крім того, мимовільний аборт частіше відбувається при СПКЯ з частотою від 42 до 73 \% [32]. У дослідженні понад L. Chitra Varanasi et al. встановлено, що 50 \% жінок у групі з СПКЯ самостійно вирішили, що не зможуть мати дітей незважаючи на те, що рівень вагітності у цій групі вищий, більшість все ще вважала, що їхня фертильність знижена [33]. Дезінформація щодо фертильності в цій віковій групі призводить до переживань і занепокоєння, тому надання вичерпної інфрормації та відкрите обговорення проблем фертильності $€$ важливими частинами лікування СПКЯ [34, 35].

Ендометріоз і СПКЯ супроводжуються зміною функціонування жіночої гіпоталамус-гіпофріз-гонади осі, але їх до цього часу не розглядають як патології, що пов'язані одна з одною. Ендометріоз - доброякісне, естрогенозалежне гінекологічне захворювання; однак через супутні захворювання та хронічний характер це дуже важлива медична, соціальна та економічна проблема. Ендометріоз $€$ поширеним гінекологічним захворюванням у світі [36]. Це захворювання вражає 10-15 \% жінок репродуктивного віку та 35-50 \% жінок із тазовим болем та/або безпліддям. Однак необхідно зазначити, що є випадки захворювання на ендометріоз після менопаузи, причому це трапляється й у жінок підліткового віку [37]. Переважна більшість випадків ендометріозу
Вісник медичних і біологічних досліджень Bulletin of Medical and Biological Research
$4(10), 2021$ 
виникає у жінок між менархе і менопаузою. Пік захворювання припадає на період від 25 до 45 років [38]. Літературні дані свідчать, що ендометріоз виявляється у 0,1-53 \% жінок, оперованих лапароскопічно або лапаротомно, з них 12-32 \% жінки після діагностичної лапароскопії з метою усунення тазового болю та 10-60 \% пацієнток після діагностичної лапароскопії через інвалідність [39-41]. Ендометріоз у 7 \% жінок пов'язаний з їх генетичною схильністю. Це захворювання було виявлено у 2 \% жінок, яким перев'язували маткові труби, і $17 \%$ жінок після операції з видалення яєчників $[42,43]$. У світовій літературі також повідомляється про виникнення вогнищ ендометріозу в плодів [44]. Ризик розвитку ендометріозу найнижчий у чорношкірих жінок, найвищий в азіаток. Жінки європеоїдної раси мають вищий ризик захворіти, ніж чорношкірі жінки [45]. Ендометріоз є проблемою величезного значення не тільки з медичної та соціальної точки зору, але й з економічної точки зору. Щорічні витрати на лікування ендометріозу в Європі коливаються від 0,8 млрд євро до 12,5 млрд євро залежно від країни і можна порівняти з іншими хронічними захворюваннями, такими як цукровий діабет [46].

Ендометріоз має значний негативний вплив на аспекти соціального життя, сім'ї, сексуального, навчального та професійного життя [46-48]. Біль і пов'язана з цим дисорункція організму погіршують якість життя і знижують профресійну продуктивність. У випадках, коли немає чіткої причини або ліків, захворювання може бути хронічним і рецидивним. Через свій вплив на сексуальність і фертильність він може мати негативний вплив на партнерські стосунки.

Етіологія ендометріозу, стану, що діагностується, коли тканина ендометрія проліферує за межі матки, дуже неоднозначна $[49,50]$. Жінки з ендометріозом можуть відчувати сильний тазовий біль, особливо під час менструації (дисменорея), і рясні менструальні кровотечі, а також зниження фрертильності [49]. Дослідження причин ендометріозу в основному зосереджуються на поясненнях того, як клітини ендометрія 3'являються в очеревинній порожнині та інших ділянках тіла [51], ідентифрікації сприятливих генів і фракторів ризику навколишнього середовища $[52,53]$, а також дослідження стероїдних та імунологічних шляхів, які сприяють утворенню та зростанню ураження [52, 54].

Справжню поширеність ендометріозу в будьякій популяції важко визначити через ряд фракторів. Приблизна поширеність варіюється залежно від географрічного регіону, групи пацієнтів, які досліджуються, наявності чи відсутності симптомів та методу діагностики. Крім того, значна кількість випадків може ніколи не бути діагностованою, оскільки паці$\epsilon$ нт не звертається за медичною допомогою через відсутність симптомів або нормалізацію наявних симптомів [55-59]. Оскільки діагноз зазвичай підтверджується лише після лапароскопії, дані про безсимптомних пацієнтів, ймовірно, є недостатніми [60]. Крім того, епідеміологічні дослідження ендометріозу стикаються з низкою методологічних проблем, таких як визначення захворювання, упередження відбору та проблеми, пов'язані з проведенням когортних досліджень або досліджень випадок-контроль [42, 61].

Безпліддя $є$ відносно частим симптомом у пацієнтів з ендометріозом. Від 30 до 50 \% жінок 3 ендометріозом можуть мати безпліддя [62]. Ендометріоз може впливати на фрертильність кількома способами: викривлення анатомії малого таза, спайки, рубці маткових труб, запалення тазових структур, зміна фрункціонування імунної системи, зміни в гормональному середовищі яйцеклітин, порушення імплантації та зміна якості яйцеклітини. Часто це безпліддя залишається непоясненим через затримку діагностики, що викликає значний рівень стресу [63].

За даними наукових досліджень, СПкЯ та ендометріоз $є$ захворюваннями, які часто зустрічаються у жінок репродуктивного віку [64]. Обидва негативно впливають на народжуваність [65]. Brincat et al. повідомили, що 10 безплідної популяції мали ендометріоз і СПКЯ, що становить 48 усіх пацієнток із СПКЯ [66]. Щоб покращити успіх індукції овуляції, McGovern et al. обговорили важливість скринінгу інших причин безпліддя у жінок із СПКЯ, в тому числі ендометріозу [67].

Варіантом другої або третьої лінії лікування безпліддя при СПКЯ є лапароскопічне оперативне втручання [68], яке, ймовірно, $є$ ефективним у зв'язку 3 наявністю супутнього ендометріозу. Примітно, що лише кілька досліджень результатів лапароскопій включали інорормацію про лапароскопічно підтверджений ендометріоз [69, 70]. Дослідження показали, що після відновлення овуляторного статусу при СПКЯ, причина безпліддя стає незрозумілою. Meuleman et al. дослідили, що майже 50 \% таких пацієнтів мали ендометріоз під час лапароскопії [71]. У дослідженні Kristin et al. виявили, що частота ендометріозних уражень у жінок із СПкЯ становила $72 \%$ (95 \% ДІ, 62-79 \%) при підозрі на ендометріоз і 70 \% (95 \% ДІ, 54-82 \%) для підтверджених випадків [72]. Ця частота узгоджується з результатами, опублікованими Janssen et al., які у підлітків із хронічним тазовим болем після лапароскопії виявили частоту ендометріозу в 62 \% (95 \% ДІ, 58,4-64,8 \%) [73]. Результати інших досліджень показали, що частота ендометріозу у жінок із СПкЯ коливалася від 11 до 16 \% (95 \% ДІ, 7-25 \%) [74].

Автори зазначають, що жінкам із СПКЯ набагато рідше роблять лапароскопію під час обстеження на безпліддя, оскільки овуляторна дисорунцція є відомою основною причиною зниження плідності. Крім того, оскільки допоміжні репродуктивні технології 
заміняють лапароскопію як метод лікування, жінкам із СПКЯ все частіше пропонують екстракорпоральне запліднення як альтернативу $[75,76]$. Ановуляція не $є$ типовою серед жінок з ендометріозом [77], а ендометріоз сам по собі є відомим фрактором ризику безпліддя [78]; таким чином, жінки з СПкя не розглядаються з точки зору підвищеного ризику ендометріозу. Крім того, жінки з СПкя зазвичай мають підвищений індекс маси тіла, що є захисним орактором для діагностики ендометріозу [79]. Ана-

\section{СПИСОК ЛІТЕРАТУРИ}

1. Prevalence of polycystic ovary syndrome among the privately insured, United States, 2003-2008 / E. M. Okoroh, W. C. Hooper, H. K. Atrash [et al.] // Obstet. Gynecol. - 2012. - Vol. 207 (4). - P. 299. DOI: 10.1016/j.ajog.2012.07.023.

2. The prevalence of polycystic ovary syndrome in a community sample assessed under contrasting diagnostic criteria / W. A. March, V. M. Moore, K. J. Willson [et al.] // Hum. Reprod. - 2010. - Vol. 25 (2). - P. 544-551. DOI: 10.1093/humrep/dep399.

3. The prevalence and features of the polycystic ovary syndrome in an unselected population / R. Azziz, K. S. Woods, R. Reyna [et al.] // J. Clin. Endocrinol. Metab. -2004. - Vol. 89 (6). - P. 2745-2749. DOI: 10.1210/jc.2003-032046.

4. A review: Brief insight into Polycystic Ovarian syndrome / J. Bulsara, P. Patel, A. Soni, S. Acharya // Endocrine and Metabolic Science. - 2021. - Vol. 3. 100085. DOI: 10.1016/j.endmts.2021.100085.

5. An epidemiological survey: effect of predisposing factors for PCOS in Indian urban and rural population / R. V. Bharathi, S. Swetha, J. Neerajaa [et al.] // Middle East Fertil. Soc. J. -2017. - Vol. 22 (4). P. 313-316. DOI: 10.1016/j.mefs.2017.05.007.

6. Polycystic ovarian syndrome and insulin resistance in white and Mexican American women: A comparison of two distinct populations / R. P. Kauffman, V. M. Baker, P. Dimarino [et al.] // Am. J. Obstet. Gynecol. - 2002. Vol.187(5).-P. 1362-1369. DOI: 10.1067/mob.2002.126650.

7. Lin $Y$. The relationship between changes in sex hormone level and physiology and disease of women in different age groups / Y. Lin, L. Li, R. Xu // Henan J. Prevent. Med. - 2010. - Vol. 21. - P. 179-181.

8. The Androgen Excess and PCOS Society criteria for the polycystic ovary syndrome: The complete task force report / R. Azziz, E. Carmina, D. Dewailly [et al.] // Fertil. Steril. - 2009. - Vol. 91 (2). - P. 456-488. DOI: 10.1016/j. fertnstert.2008.06.035.

9. The prevalence of polycystic ovarian syndrome in Chinese women: a meta-analysis / Q. Wu, J. Gao, D. Bai [et al.] // Ann. Palliat. Med. - 2021. - Vol. 10 (1). - P. 74-87. DOI: 10.21037/apm-20-1893.

10. Geographical prevalence of polycystic ovary syndrome as determined by region and race/ethnicity / W. M. Wolf, R. A. Wattick, O. N. Kinkade [et al.] // Int. J. Environ. Res. Public. Health. - 2018. - Vol. 15 (11). P. 2589. DOI: 10.3390/ijerph15112589.

11. Carmina E. Diagnosis of polycystic ovary syndrome: From NIH criteria to ESHRE-ASRM guidelines / E. Carmina // Minerva Ginecol. - 2004. - Vol. 56 (1). - P. 1-6. ліз літературних джерел показав, що поширеність ендометріозу в жінок із СПкЯ необхідно вивчати.

\section{ВИСНОВКИ}

Враховуючи високу поширеність синдрому полікістозних яєчників, ендометріозу, а також їх коморбідного перебігу, виникає необхідність розуміння механізмів розвитку безпліддя у таких пацієнток, що дозволить обґрунтувати тактику лікування безпліддя, спричиненого даними захворюваннями.

12. PCOS according to the Rotterdam consensus criteria: change in prevalence among WHO-II anovulation and association with metabolic factors / F. J. Broekmans, E. A. Knauff, O. Valkenburg [et al.] // BJOG. - 2006. - Vol. 113 (10). - P. 1210-1217. DOI: 10.1111/j.14710528.2006.01008.x.

13. Polycystic ovary syndrome: controversies and challenges / J. M. Soares Júnior, M. C. Baracat, G. A. Maciel, E. C. Baracat // Rev. Assoc. Med. Bras. (1992). - 2015. - Vol. 61 (6). - P. 485-487. DOI: 10.1590/18069282.61.06.485.

14. Prevalence of metabolic syndrome in women with polycystic ovary syndrome attending an infertility clinic in a tertiary care hospital in south India / K. Mandrelle, M. S. Kamath, D. J. Bondu [et al.] // J. Hum. Reprod. Sci. 2012. - Vol. 5 (1). - P. 26-31. DOI: 10.4103/0974-1208.97791.

15. The prevalence of polycystic ovary syndrome in a normal population according to the Rotterdam criteria versus revised criteria including anti-Mullerian hormone / M. P. Lauritsen, J. G. Bentzen, A. Pinborg [et al.] // Hum. Reprod. - 2014. - Vol. 29 (4). - P. 791-801. DOI: 10.1093/ humrep/det469.

16. Prevalence of polycystic ovary syndrome in unselected women from southern China / X. Chen, D. Yang, Y. Mo [et al.] // Eur. J. Obstet. Gynecol. Reprod. Biol. - 2008. - Vol. 139. - P. 59-64. DOI: 10.1016/j.ejogrb.2007.12.018.

17. A survey of the polycystic ovary syndrome in the Greek island of Lesbos: hormonal and metabolic profile / E. Diamanti-Kandarakis, C. R. Kouli, A. T. Bergiele [et al.] // J. Clin. Endocrinol. Metab. - 1999. - Vol. 84 (11). - P. 40064011. DOI: 10.1210/jcem.84.11.6148.

18. The prevalence and phenotypic features of polycystic ovary syndrome: a systematic review and metaanalysis / G. Bozdag, S. Mumusoglu, D. Zengin [et al.] // Hum. Reprod. - 2016. - Vol. 31 (12). - P. 2841-2855. DOI: 10.1093/humrep/dew218.

19. Rao M. Cross-sectional study on the knowledge and prevalence of PCOS at a Multiethnic University / M. Rao, K. S. Broughton, M. J. LeMieux // Prog. Prev. Med. (N Y). 2020. - e0028. DOI: 10.1097/pp9.0000000000000028.

20. Centers for disease control and prevention. PCOS (Polycystic ovary syndrome) and diabetes. - Access mode: https://www.cdc.gov/diabetes/basics/pcos.html?CDC_AA refVal=https $\% 3 \mathrm{~A} \% 2 \mathrm{~F} \% 2 \mathrm{Fwww}$. cdc.gov\%2Fdiabetes $\% 2 \mathrm{Fli}$ brary\%2Fspotlights\%2Fpcos.html. 2019.

21. Patel S. Polycystic ovary syndrome (PCOS), an inflammatory, systemic, lifestyle endocrinopathy / S. Patel //
$4(10), 2021$ 
J. Steroid Biochem. Mol. Biol. - 2018. - Vol. 182. - P. 2736. DOI: 10.1016/j.jsbmb.2018.04.008.

22. Racial and ethnic differences in the polycystic ovary syndrome metabolic phenotype / L. Engmann, S. Jin, F. Sun [et al.] // Am. J. Obstet. Gynecol. - 2017. - Vol. 216 (5). P. 493.e1-e13. DOI: 10.1016/j.ajog.2017.01.003.

23. Delayed diagnosis and a lack of information associated with dissatisfaction in women with polycystic ovary syndrome / M. Gibson-Helm, H. Teede, A. Dunaif, A. Dokras // J. Clin. Endocrinol. Metab. - 2017. - Vol. 102 (2). - P. 604-612. DOI: 10.1210/jc.2016-2963.

24. Prevalence of polycystic ovarian syndrome in Indian adolescents / R. Nidhi, V. Padmalatha, R. Nagarathna, R. Amritanshu // J. Pediatr Adolesc. Gynecol. - 2011. Vol. 24 (4). - P. 223-227. DOI: 10.1016/j.jpag.2011.03.002.

25. A cross sectional study of polycystic ovarian syndrome among young women in Bhopal, Central India / M. Gupta, D. Singh, M. Toppo [et al.] // Int. J. Community Med. Public. Health. - 2018. - Vol. 5 (1). - P. 95-100. DOI: 10.18203/2394-6040.ijcmph20175603.

26 . The prevalence of polycystic ovary syndrome in reproductive-aged women of different ethnicity: a systematic review and meta-analysis / T. Ding, P. J. Hardiman, I. Petersen [et al.] // Oncotarget. - 2017. - Vol. 8 (56). P. 96351-96358. DOI: 10.18632/oncotarget.19180.

27. Epidemiology, pathogenesis, genetics \& management of polycystic ovary syndrome in India / M. A. Ganie, V. Vasudevan, I. A. Wani [et al.] // Indian J. Med. Res. - 2019. - Vol. 150 (4). - P. 333-44. DOI: 10.4103/ijmr. IJMR_1937_17.

28. Prevalence of polycystic ovary syndrome in women in China: a large community-based study / R. Li, Q. Zhang, D. Yang [et al.] // Hum. Reprod. - 2013. - Vol. 28 (9). P. 2562-2569. DOI: 10.1093/humrep/det262.

29. Cross-sectional study of the prevalence of polycystic ovary syndrome in rural and urban populations / R. Deswal, S. Nanda, V. S. Ghalaut [et al.] // Int. J. Gynaecol. Obstet. 2019. - Vol. 146 (3). - P. 370-389. DOI: 10.1002/ijgo.12893.

30. Teede H. Polycystic ovary syndrome: a complex condition with psychological, reproductive and metabolic manifestations that impacts on health across the lifespan / H. Teede, A. Deeks, L. Moran // BMC Med. - 2010. Vol. 8. - P. 41. DOI: 10.1186/1741-7015-8-41.

31. Brassard M. Basic infertility including polycystic ovary syndrome / M. Brassard, Y. AinMelk, J. P. Baillargeon // Med. Clin. North. Am. - 2008. - Vol. 92 (5). - P. 1163-1192. DOI: 10.1016/j.mcna.2008.04.008.

32. Sirmans S. M. Epidemiology, diagnosis, and management of polycystic ovary syndrome / S. M. Sirmans, K. A. Pate // Clin. Epidemiol. - 2013. - Vol. 6. - P. 1-13. DOI: $10.2147 / C L E P . S 37559$

33. Polycystic ovarian syndrome: Prevalence and impact on the wellbeing of Australian women aged 16-29 years / L. C. Varanasi, A. Subasinghe, Y. L. Jayasinghe [et al.] // J. Obstet. Gynaecol. - 2018. - Vol. 58 (2). - P. 222-233. DOI: 10.1111/ajo.12730.

34. Morris S. What does a diagnostic label of "polycystic ovary syndrome' really mean in adolescence? a review of current practice recommendations / S. Morris, S. Grover, M. A. Sabin // Clin. Obes. - 2016. - Vol. 6 (1). - P. 1-18. DOI: $10.1111 /$ cob.12123.

35. Kaczmarek C. Health related quality of life in adolescents and young adults with polycystic ovary syndrome: a systematic review / C. Kaczmarek, D. M. Haller, M. Yaron // J. Pediatr. Adolesc. Gynecol. - 2016. - Vol. 29 (6). - P. 551-557. DOI: 10.1016/j. jpag.2016.05.006.

36. A systematic review on endometriosis during pregnancy: Diagnosis, misdiagnosis, complications and outcomes / U. L. R. Maggiore, S. Ferrero, G. Mangili [et al.] // Hum. Reprod. Update. - 2016. - Vol. 22 (1). - P. 70-103. DOI: 10.1093/humupd/dmv045.

37. Potential involvement of iron in the pathogenesis of peritoneal endometriosis / S. Defrère, J. C. Lousse, R. González-Ramos [et al.] // Mol. Hum. Reprod. - 2008. - Vol. 14 (7). - P. 377-385. DOI: 10.1093/molehr/gan033.

38. Eskenazi B. Epidemiology of endometriosis / B. Eskenazi, M. Warner // Obstet. Gynecol. Clin. N. Am. - 1997. - Vol. 24 (2). - P. 235-258. DOI: 10.1016/s08898545(05)70302-8.

39. Lu P. Endometriosis: Current management / P. Lu, S. Ory // Mayo Clin. Proc. - 1995. - Vol. 70 (5). - P. 453463. DOI: $10.4065 / 70.5 .453$.

40. Dmowski W. Endometriosis at the end of the millenium; the controversy remains / W. Dmowski // Pol. J. Gyn. Investig. - 1999. - Vol. 1. - P. 175-186.

41. Global gene profiling in human endometrium during the window of implantation / L. C. Kao, S. Tulac, S. Lobo [et al.] // Endocrinology. - 2002. - Vol. 143 (6). - P. 2119-2138. DOI: 10.1210/en.143.6.2119.

42. Cramer D. W. The epidemiology of endometriosis / D. W. Cramer, S. A. Missmer // Ann. N. Y. Acad. Sci. - 2002. Vol. 955. - P. 11-22. DOI: 10.1111/j.1749-6632.2002.tb02761.x.

43. Gadomska H. Endometrioza / H. Gadomska, P. Kamiński, L. Marianowski // Medipress Ginekol. - 1997. - Vol. 3. - P. 2-5.

44. New evidence of the presence of endometriosis in the human fetus / P. G. Signorile, F. Baldi, R. Bussani [et al.] // Reprod. Biomed. Online. - 2010. - Vol. 21 (1). P. 142-147. DOI: 10.1016/j.rbmo.2010.04.002.

45. Laparoscopy on the diagnosis and management of pelvic pain in adolescents / D. P. Goldstein, C. de Cholnoky, S. J. Emans, J. M. Leventhal // J. Reprod. Med. - 1980. Vol. 24. - P. 251-256.

46. The burden of endometriosis: costs and quality of life of women with endometriosis and treated in referral centres / S. Simoens, G. Dunselman, C. Dirksen [et al.] // Hum. Reprod. - 2012. - Vol. 27. - P. 1292-1299. DOI: 10.1093/ humrep/des073.

47. Impact of endometriosis on quality of life and work productivity: A multi-center study across ten countries / K. E. Nnoaham, L. Hummelshoj, P. Webster [et al.] // Fertil. Steril. - 2011. - Vol. 96 (2). - P. 366-373. DOI: 10.1016/j. fertnstert.2011.05.090.

48. The significant effect of endometriosis on physical, mental and social well-being: Results from an inter-national cross-sectional survey / A. A. De Graaff, T. M. D'Hooghe, G. A. Dunselman [et al.] // Hum. Reprod. - 2013. - Vol. 28 (10). - P. 2677-2685. DOI: 10.1093/humrep/det284.

49. Endometriosis / S. E. Bulun, B. D. Yilmaz, C. Sison [et al.] // Endocr. Rev. - 2019. - Vol. 40 (4). - P. 1048-1079. DOI: 10.1210/er.2018-00242.

50. Burney R. O. Pathogenesis and pathophysiology of endometriosis / R. O. Burney, L. C. Giudice // Fertil. Steril. - 2012. - Vol. 98 (3). - P. 511-519. DOI: 10.1016/j. fertnstert.2012.06.029. 
51. The perinatal origins of major reproductive disorders in the adolescent: research avenues / I. Brosens, A. Ćurčić, T. Vejnović [et al.] // Placenta. - 2015. - Vol. 36 (4). P. 341-344. DOI: 10.1016/j.placenta.2015.01.003.

52. Hypothetical roadmap towards endometriosis: Prenatal endocrine-disrupting chemical pollutant exposure, anogenital distance, gut-genital microbiota and subclinical infection / P. García-Peñarrubia, A. J. Ruiz-Alcaraz, M. Martínez-Esparza [et al.] // Hum. Reprod. Update. 2020. - Vol. 26 (2). - P. 214-246. DOI: 10.1093/humupd/ dmz044.

53. Genetic variants underlying risk of endometriosis: Insights from meta-analysis of eight genome-wide association and replication datasets / N. Rahmioglu, D. R. Nyholt, A. P. Morris [et al.] // Hum. Reprod. Update. 2014. - Vol. 20 (5). - P. 702-716. DOI: 10.1093/humupd/ dmu015.

54. Progesterone and estrogen signaling in the endometrium: What goes wrong in endometriosis? / R. M. Marquardt, T. H. Kim, J. H. Shin, J. W. Jeong // Int. J. Mol. Sci. - 2019. Vol. 20 (15). - P. 3822. DOI: 10.3390/ijms20153822.

55. Eisenberg V. H. Epidemiology of endometriosis: a large population-based database study from a healthcare provider with 2 million members / V. H. Eisenberg, C. Weil, G. Chodick, V. Shalev // BJOG. - 2018. - Vol. 125 (1). P. 55-62. DOI: 10.1111/1471-0528.14711.

56. Fuldeore M. J. Prevalence and symptomatic burden of diagnosed endometriosis in the United States: national estimates from a cross-sectional survey of 59,411 women / M. J. Fuldeore, A. M. Soliman // Gynecol. Obst. Investig. 2017. - Vol. 82 (5). - P. 453-461. DOI: 10.1159/000452660.

57. Incidence and estimated prevalence of endometriosis and adenomyosis in Northeast Italy: a data linkage study I C. Morassutto, L. Monasta, G. Ricci [et al.] // PLoS One. - 2016. - Vol. 11 (4). - e0154227. DOI: 10.1371/journal. pone.0154227.

58. Questionnaire-based prevalence of endometriosis and its symptoms in Jordanian women / M. Al-Jefout, A. Nesheiwat, B. Odainat [et al.] // Biomed. Pharmacol. J. 2017. - Vol. 10 (2). - P. 699-706. DOI: 10.13005/bpj/1158.

59. Prevalence of endometriosis and its symptoms among young Jordanian women with chronic pelvic pain refractory to conventional therapy / M. Al-Jefout, N. Alnawaiseh, S. Yaghi, A. Alqaisi // J. Obst. Gynaecol. Can. - 2018. - Vol. 40 (2). - P. 165-170. DOI: 10.1016/j. jogc.2017.06.042.

60 . The epidemiology of endometriosis is poorly known since the pathophysiology and the diagnosis are unclear / P. R. Koninckx, U. Anastasia, L. Adamyan [et al.] // Best. Pract. Res. Clin. Obstet. Gynaecol. - 2020. - Vol. 71. P. 14-26. DOI: 10.1016/j.bpobgyn.2020.08.005.

61. Prevalence of endometriosis in women undergoing laparoscopic surgery for various gynaecological indications at a Jordanian referral centre: gaining insight into the epidemiology of an important women's health problem I N. Muhaidat, S. Saleh, K. Fram [et al.] // BMC Women's Health. - 2021. - Vol. 21. - P. 381. DOI: 10.1186/s12905021-01530-y.

62. Incidence of laparoscopically confirmed endometriosis by demographic, anthropometric, and lifestyle factors / S. A. Missmer, S. E. Hankinson, D. Spiegelman [et al.] // Am. J. Epidemiol. - 2004. - Vol. 160 (8). - P. 784-796. DOI: 10.1093/aje/kwh275.
63. Clinical diagnosis of endometriosis: a call to action / S. K. Agarwal, C. Chapron, L. C. Giudice [et al.] // Am. J. Obstet. Gynecol. - 2019. - Vol. 220 (4). - P. 354.e1-e12. DOI: 10.1016/j.ajog.2018.12.039.

64. Recommendations from the international evidencebased guideline for the assessment and management of polycystic ovary syndrome / H. J. Teede, M. L. Misso, M. F. Costello [et al.] // Hum. Reprod. - 2018. - Vol. 33 (9). - P. 1602-1618. DOI: 10.1093/humrep/dey256.

65. ESHRE guideline: management of women with endometriosis / G. A. Dunselman, N. Vermeulen, C. Becker [et al.] // Hum. Reprod. Embryol. - 2014. - Vol. 29 (3). P. 400-412. DOI: 10.1093/humrep/det457.

66. Brincat M. Polycystic ovaries and endometriosis: a possible connection / M. Brincat, R. Galea, A. Buhagiar // Br. J. Obstet. Gynaecol. - 1994. - Vol. 101 (4). - P. 346348. DOI: 10.1111/j.1471-0528.1994.tb13625.x.

67. Utility of screening for other causes of infertility in women with "known" polycystic ovary syndrome / P. G. McGovern, R. S. Legro, E. R. Myers [et al.] // Fertil. Steril. - 2007. - Vol. 87 (2). - P. 442-444. DOI: 10.1016/j. fertnstert.2006.06.050.

68. The prevalence of incidental endometriosis in women undergoing laparoscopic ovarian drilling for clomipheneresistant polycystic ovary syndrome: a retrospective cohort study and meta-analysis / M. Hager, R. Wenzl, S. Riesenhuber [et al.] // J. Clin. Med. - 2019. - Vol. 8 (8). P. 1210. DOI: $10.3390 / \mathrm{jcm} 8081210$.

69. Perioperative androstenedione kinetics in women undergoing laparoscopic ovarian drilling: a prospective study / J. Ott, K. Mayerhofer, K. Nouri [et al.] // Endocrine. - 2014. - Vol. 47 (3). - P. 936-942. DOI: 10.1007/s12020014-0267-1.

70. Salah I. M. Office microlaparoscopic ovarian drilling (OMLOD) versus conventional laparoscopic ovarian drilling (LOD) for women with polycystic ovary syndrome / I. M. Salah // Arch. Gynecol. Obstet. - 2013. - Vol. 287 (2). - P. 361-367. DOI: 10.1007/s00404-012-2526-9.

71. D'Hooghe T. High prevalence of endometriosis in infertile women with normal ovulation and normospermic partners / C. Meuleman, B. Vandenabeele, S. Fieuws [et al.] // Fertil. Steril. - 2009. - Vol. 92 (1). - P. 68-74. DOI: 10.1016/j.fertnstert.2008.04.056.

72. Coexistence of polycystic ovary syndrome and endometriosis in women with infertility / K. J. Holoch, R. F. Savaris, D. A. Forstein [et al.] // J. Endometr. Pelvic Pain Disord. - 2014. - Vol. 6 (2). - P. 78-83. DOI: 10.5301/ je.5000181.

73. Prevalence of endometriosis diagnosed by laparoscopy in adolescents with dysmenorrhea or chronic pelvic pain: a systematic review / E. B. Janssen, A. C. Rijkers, K. Hoppenbrouwers [et al.] // Hum. Reprod. Update. - 2013. - Vol. 19 (5). - P. 570-582. DOI: 10.1093/ humupd/dmt016.

74. Kichukova D. Polycystic ovaries in association with pelvic endometriosis in infertile women diagnosed by laparoscopy / D. Kichukova // Folia Med. (Plovdiv). - 1996. - Vol. 38 (3-4). - P. 71-73.

75. Consensus on infertility treatment related to polycystic ovary syndrome / Thessaloniki ESHRE/ASRMSponsored PCOS Consensus Workshop Group // Fertil Steril. - 2008. - Vol. 89 (3). - P. 505-522. DOI: 10.1016/j. fertnstert.2007.09.041. 
76. Vause T. D. Ovulation induction in polycystic ovary syndrome / T. D. Vause, A. P. Cheung // J. Obstet. Gynaecol. Can. - 2010. - Vol. 32 (5). - P. 495-502.

77. Arumugam K. The association of anovulation and endometriosis in the infertile female / K. Arumugam, T. A. Mahmood, Y. F. Kong // Aust. N. Z. J. Obstet. Gynaecol. - 1989. - Vol. 29 (3 Pt 2). - P. 350-351. DOI: 10.1111/j.1479828x.1989.tb01761.x.

\section{REFERENCES}

1. Okoroh EM, Hooper WC, Atrash HK, Yusuf HR, Boulet SL. Prevalence of polycystic ovary syndrome among the privately insured, United States 2003-2008. Obstet Gynecol. 2012;207(4): 299.e1-e7. DOI: 10.1016/j. ajog.2012.07.023.

2. March WA, Moore VM, Willson KJ, Phillips DI, Norman RJ, Davies MJ. The prevalence of polycystic ovary syndrome in a community sample assessed under contrasting diagnostic criteria. Hum Reprod. 2010;25(2): 544-51. DOI: 10.1093/humrep/dep399.

3. Azziz R, Woods KS, Reyna R, Key TJ, Knochenhauer ES, Yildiz BO. The prevalence and features of the polycystic ovary syndrome in an unselected population. J Clin Endocrinol Metab. 2004;89(6): 2745-9. DOI: 10.1210/ jc.2003-032046.

4. Bulsara J, Patel P, Soni A, Acharya S. A review: Brief insight into Polycystic Ovarian syndrome. Endocr Metab Sci. 2021;3:100085. DOI: 10.1016/j.endmts.2021.100085.

5. Bharathi RV, Swetha S, Neerajaa J, Madhavica JV, Janani DM, Rekha SN, Ramya S, Usha B. An epidemiological survey: effect of predisposing factors for PCOS in Indian urban and rural population. Middle East Fertil Soc J. 2017;22(4): 313-6. DOI: 10.1016/j.mefs.2017.05.007.

6. Kauffman RP, Baker VM, Dimarino P, Gimpel T, Castracane VD. Polycystic ovarian syndrome and insulin resistance in white and Mexican American women: A comparison of two distinct populations. Am J Obstet Gynecol. 2002;187(5): 1362-9. DOI: 10.1067/mob.2002.126650.

7. Lin Y, Li L, Xu R. The relationship between changes in sex hormone level and physiology and disease of women in different age groups. Henan J Prevent Med. 2010;21: 17981.

8.Azziz R, CarminaE, Dewailly D, Diamanti-KandarakisE, Escobar-Morreale HF, Futterweit W, et al. The Androgen Excess and PCOS Society criteria for the polycystic ovary syndrome: The complete task force report. Fertil Steril. 2009;91(2): 456-88. DOI: 10.1016/j.fertnstert.2008.06.035.

9. Wu Q, Gao J, Bai D, Yang Z, Liao Q. The prevalence of polycystic ovarian syndrome in Chinese women: a meta-analysis. Ann Palliat Med. 2021;10(1): 74-87. DOI: 10.21037/apm-20-1893.

10. Wolf WM, Wattick RA, Kinkade ON, Olfert MD. Geographical prevalence of polycystic ovary syndrome as determined by region and race/ethnicity. Int J Environ Res Public Health. 2018;15(11): 2589. DOI: 10.3390/ ijerph15112589.

11. Carmina E. Diagnosis of polycystic ovary syndrome: From NIH criteria to ESHRE-ASRM guidelines. Minerva Ginecol. 2004;56(1): 1-6.
78. Risk factors associated with endometriosis: importance of study population for characterizing disease in the ENDO Study / C. Peterson, E. Johnstone, A. Hammoud [et al.] // Am. J. Obstet. Gynecol. - 2013. - Vol. 208 (6). P. 451.e1-e11. DOI: 10.1016/j.ajog.2013.02.040.

79. Evaluation of risk factors associated with endometriosis / R. Hemmings, M. Rivard, D. L. Olive [et al.] // Fertil. Steril. - 2004. - Vol. 81 (6). - P. 1513-1521. DOI: 10.1016/j.fertnstert.2003.10.038.

12. Broekmans FJ, Knauff EA, Valkenburg O, Laven JS, Eijkemans $\mathrm{MJ}$, Fauser BC. PCOS according to the Rotterdam consensus criteria: Change in prevalence among WHO-II anovulation and association with metabolic factors. BJOG. 2006;113(10): 1210-17. DOI: 10.1111/j.14710528.2006.01008.x.

13. Soares Júnior JM, Baracat MC, Maciel GA, Baracat EC. Polycystic ovary syndrome: controversies and challenges. Rev Assoc Med Bras (1992). 2015;61(6): 4857. DOI: $10.1590 / 1806-9282.61 .06 .485$.

14. Mandrelle K, Kamath MS, Bondu DJ, Chandy A, Aleyamma T, George K. Prevalence of metabolic syndrome in women with polycystic ovary syndrome attending an infertility clinic in a tertiary care hospital in south India. J Hum Reprod Sci. 2012;5(1): 26-31. DOI: 10.4103/0974-1208.97791.

15. Lauritsen MP, Bentzen JG, Pinborg A, Loft A, Forman JL, Thuesen LL, et al. The prevalence of polycystic ovary syndrome in a normal population according to the Rotterdam criteria versus revised criteria including antiMullerian hormone. Hum Reprod. 2014;29(4): 791-801. DOI: 10.1093/humrep/det469.

16. Chen X, Yang D, Mo Y, Li L, Chen Y, Huang Y. Prevalence of polycystic ovary syndrome in unselected women from southern China. Eur J Obstet Gynecol Reprod Biol. 2008;139: 59-64. DOI: 10.1016/j.ejogrb.2007.12.018.

17. Diamanti-Kandarakis E, Kouli CR, Bergiele AT, Filandra FA, Tsianateli TC, Spina GG, Zapanti ED, Bartzis MI. A survey of the polycystic ovary syndrome in the Greek island of Lesbos: hormonal and metabolic profile. J Clin Endocrinol Metab. 1999;84(11): 4006-11. DOI: 10.1210/ jcem.84.11.6148.

18. Bozdag G, Mumusoglu S, Zengin D, Karabulut E, Yildiz BO. The prevalence and phenotypic features of polycystic ovary syndrome: a systematic review and meta-analysis. Hum Reprod. 2016;31(12): 2841-55. DOI: 10.1093/humrep/dew218.

19. Rao M, Broughton KS, LeMieux MJ. Cross-sectional study on the knowledge and prevalence of PCOS at a Multiethnic University. Prog Prev Med (N Y). 2020:e0028. DOI: $10.1097 / p p 9.0000000000000028$.

20. Centers for disease control and prevention. PCOS (Polycystic ovary syndrome) and diabetes. Available at https://www.cdc.gov/diabetes/basics/pcos.html?CDC_AA refVal=https $\% 3 \mathrm{~A} \% 2 \mathrm{~F} \% 2 \mathrm{Fwww} . \mathrm{cdc} . \mathrm{gov} \% 2 \mathrm{Fdiabetes} \% 2 \mathrm{Fli}$ brary\%2Fspotlights\%2Fpcos.html. 2019.

21. Patel S. Polycystic ovary syndrome (PCOS), an inflammatory, systemic, lifestyle endocrinopathy. J Steroid Biochem Mol Biol. 2018;182: 27-36. DOI: 10.1016/j. jsbmb.2018.04.008. 
22. Engmann L, Jin S, Sun F, Legro RS, Polotsky AJ, Hansen KR, et al. Reproductive Medicine Network. Racial and ethnic differences in the polycystic ovary syndrome metabolic phenotype. Am J Obstet Gynecol. 2017;216(5): 493.e1-e13. DOI: 10.1016/j.ajog.2017.01.003.

23. Gibson-Helm M, Teede $H$, Dunaif A, Dokras A. Delayed diagnosis and a lack of information associated with dissatisfaction in women with polycystic ovary syndrome. J Clin Endocrinol Metab. 2017;102(2): 604-12. DOI: 10.1210/ jc.2016-2963.

24. Nidhi R, Padmalatha V, Nagarathna R, Amritanshu R. Prevalence of polycystic ovarian syndrome in Indian adolescents. J Pediatr Adolesc Gynecol. 2011;24(4): 223-7. DOI: 10.1016/j.jpag.2011.03.002.

25. Gupta M, Singh D, Toppo M, Priya A, Sethia S, Gupta P. A cross sectional study of polycystic ovarian syndrome among young women in Bhopal, Central India. Int J Community Med Public Health. 2018;5(1): 95-100. DOI: 10.18203/2394-6040.ijcmph20175603.

26. Ding T, Hardiman PJ, Petersen I, Wang FF, Qu F, Baio G. The prevalence of polycystic ovary syndrome in reproductive-aged women of different ethnicity: A systematic review and meta-analysis. Oncotarget. 2017;8(56): 963518. DOI: 10.18632/oncotarget.19180.

27. Ganie MA, Vasudevan V, Wani IA, Baba MS, Arif T, Rashid A. Epidemiology, pathogenesis, genetics \& management of polycystic ovary syndrome in India. Indian J Med Res. 2019;150(4): 333-44. DOI: 10.4103/ijmr. IJMR 1937_17.

28. Li R, Zhang Q, Yang D, Li S, Lu S, Wu X, et al. Prevalence of polycystic ovary syndrome in women in China: a large community-based study. Hum Reprod. 2013;28(9): 2562-9. DOI: 10.1093/humrep/det262.

29. Deswal R, Nanda S, Ghalaut VS, Roy PS, Dang AS. Cross-sectional study of the prevalence of polycystic ovary syndrome in rural and urban populations. Int J Gynaecol Obstet. 2019;146(3): 370-9. DOI: 10.1002/ijgo.12893.

30. Teede H, Deeks A, Moran L. Polycystic ovary syndrome: a complex condition with psychological, reproductive and metabolic manifestations that impacts on health across the lifespan. BMC Med. 2010;8: 41. DOI: 10.1186/1741-7015-8-41.

31. Brassard M, AinMelk Y, Baillargeon JP. Basic infertility including polycystic ovary syndrome. Med Clin North Am. 2008;92(5): 1163-92. DOI: 10.1016/j.mcna.2008.04.008.

32. Sirmans SM, Pate KA. Epidemiology, diagnosis, and management of polycystic ovary syndrome. Clin Epidemiol. 2013;6: 1-13. DOI: 10.2147/CLEP.S37559.

33. Varanasi LC, Subasinghe A, Jayasinghe $Y L$, Callegari ET, Garland SM, Gorelik A, Wark JD. Polycystic ovarian syndrome: Prevalence and impact on the wellbeing of Australian women aged 16-29 years. J Obstet Gynaecol. 2018;58(2): 222-33. DOI: 10.1111/ajo.12730.

34. Morris S, Grover S, Sabin MA. What does a diagnostic label of 'polycystic ovary syndrome' really mean in adolescence? a review of current practice recommendations. Clin Obes. 2016;6(1): 1-18. DOI: 10.1111/cob.12123.

35. Kaczmarek C, Haller DM, Yaron M. Health related quality of life in adolescents and young adults with polycystic ovary syndrome: a systematic review. J Pediatr Adolesc Gynecol. 2016;29(6): 551-7. DOI: 10.1016/j. jpag.2016.05.006.
36. Maggiore ULR, Ferrero S, Mangili G, Bergamini A, Inversetti A, Giorgione V, Viganò $P$, Candiani $M$. A systematic review on endometriosis during pregnancy: Diagnosis, misdiagnosis, complications and outcomes. Hum Reprod Update. 2016;22(1): 70-103. DOI: 10.1093/ humupd/dmv045.

37. Defrère S, Lousse JC, González-Ramos R, Colette S, Donnez J, Van Langendonckt A. Potential involvement of iron in the pathogenesis of peritoneal endometriosis. Mol Hum Reprod. 2008;14(7): 377-85. DOI: 10.1093/molehr/ gan033.

38. Eskenazi B, Warner M. Epidemiology of endometriosis. Obstet Gynecol Clin N Am. 1997;24(2): 23558. DOI: 10.1016/s0889-8545(05)70302-8.

39. Lu P, Ory S. Endometriosis: Current management. Mayo Clin. Proc. 1995;70(5): 453-63. DOI: 10.4065/70.5.453.

40. Dmowski $W$. Endometriosis at the end of the millenium; the controversy remains. Pol J Gyn Investig. 1999;1: 175-86.

41. Kao LC, TulacS, Lobo S, ImaniB, Yang JP, GermeyerA, et al. Global gene profiling in human endometrium during the window of implantation. Endocrinology. 2002;143(6): 2119-38. DOI: 10.1210/en.143.6.2119.

42. Cramer DW, Missmer SA. The epidemiology of endometriosis. Ann N Y Acad Sci. 2002;955: 11-22. DOI: 10.1111/j.1749-6632.2002.tb02761.x.

43. Gadomska H, Kamiński P, Marianowski L. Endometrioza. Medipress Ginekol. 1997;3: 2-5.

44. Signorile PG, Baldi F, Bussani R, D'Armiento M, De Falco M, Boccellino M, Quagliuolo L, Baldi A. New evidence of the presence of endometriosis in the human fetus. Reprod Biomed Online. 2010;21(1): 142-7. DOI: 10.1016/j. rbmo.2010.04.002.

45. Goldstein DP, de CholnokyC, EmansSJ, LeventhalJM. Laparoscopy on the diagnosis and management of pelvic pain in adolescents. J Reprod Med. 1980;24: 251-6.

46. Simoens S, Dunselman G, Dirksen C, Hummelshoj L, Bokor A, Brandes I, et al. The burden of endometriosis: costs and quality of life of women with endometriosis and treated in referral centres. Hum Reprod. 2012;27:1292-9. DOI: 10.1093/humrep/des073.

47. Nnoaham KE, Hummelshoj L, Webster P, d'Hooghe T, de Cicco Nardone F, de Cicco Nardone C, et al. Impact of endometriosis on quality of life and work productivity: a multicenter study across ten countries. Fertil Steril. 2011;96(2): 366-73. DOI: 10.1016/j.fertnstert.2011.05.090.

48. De Graaff AA, D'Hooghe TM, Dunselman GA, Dirksen CD, Hummelshoj L. The significant effect of endometriosis on physical, mental and social well-being: Results from an inter-national cross-sectional survey. Hum Reprod. 2013;28(10): 2677-85. DOI: 10.1093/humrep/ det284.

49. Bulun SE, Yilmaz BD, Sison C, Miyazaki K, Bernardi L, Liu S, et al. Endometriosis. Endocr Rev. 2019;40(4): 1048-79. DOI: 10.1210/er.2018-00242.

50. Burney RO, Giudice LC. Pathogenesis and pathophysiology of endometriosis. Fertil Steril. 2012;98(3): 511-9. DOI: 10.1016/j.fertnstert.2012.06.029.

51. BrosensI, ĆurčićA, VejnovićT, GargettCE, Brosens JJ, Benagiano $G$. The perinatal origins of major reproductive disorders in the adolescent: research avenues. Placenta. 2015;36(4): 341-4. DOI: 10.1016/j.placenta.2015.01.003.

52. García-Peñarrubia P, Ruiz-Alcaraz AJ, Martínez-
ISSN 2706-6282(print)

ISSN 2706-6290(online) 
Esparza M, Marín P, Machado-Linde F. Hypothetical roadmap towards endometriosis: Prenatal endocrinedisrupting chemical pollutant exposure, anogenital distance, gut-genital microbiota and subclinical infections. Hum Reprod Update. 2020;26(2): 214-6. DOI: 10.1093/humupd/ dmz044.

53. Rahmioglu N, Nyholt DR, Morris AP, Missmer SA, Montgomery GW, Zondervan KT. Genetic variants underlying risk of endometriosis: Insights from metaanalysis of eight genome-wide association and replication datasets. Hum Reprod Update. 2014;20(5): 702-16. DOI: 10.1093/humupd/dmu015.

54. Marquardt RM, Kim TH, Shin JH, Jeong JW. Progesterone and estrogen signaling in the endometrium: What goes wrong in endometriosis? Int $\mathrm{J}$ Mol Sci. 2019;20(15): 3822. DOI: 10.3390/ijms20153822.

55. Eisenberg VH, Weil C, Chodick G, Shalev V. Epidemiology of endometriosis: a large population-based database study from a healthcare provider with 2 million members. BJOG. 2018;125(1): 55-62. DOI: 10.1111/14710528.14711

56. Fuldeore MJ, Soliman AM. Prevalence and symptomatic burden of diagnosed endometriosis in the United States: national estimates from a cross-sectional survey of 59,411 women. Gynecol Obst Investig. 2017;82(5): 453-61. DOI: 10.1159/000452660.

57. Morassutto C, MonastaL, RicciG, BarboneF, RonfaniL. Incidence and estimated prevalence of endometriosis and adenomyosis in Northeast Italy: a data linkage study. PLoS One. 2016;11(4): e0154227. DOI: 10.1371/journal. pone.0154227.

58. Al-Jefout M, Nesheiwat A, Odainat B, Sami R, Alnawaiseh N. Questionnaire-based prevalence of endometriosis and its symptoms in Jordanian women. Biomed Pharmacol J. 2017;10(2): 699-706. DOI: 10.13005/ bpj/1158.

59. Al-Jefout $\mathrm{M}$, Alnawaiseh $\mathrm{N}$, Yaghi $\mathrm{S}$, Alqaisi $\mathrm{A}$. Prevalence of endometriosis and its symptoms among young Jordanian women with chronic pelvic pain refractory to conventional therapy. J Obst Gynaecol Can. 2018;40(2): 165-70. DOI: 10.1016/j.jogc.2017.06.042.

60. Koninckx PR, Anastasia U, Adamyan L, Tahlak M, Keckstein J, Martin DC. The epidemiology of endometriosis is poorly known since the pathophysiology and the diagnosis are unclear. Best Pract Res Clin Obstet Gynaecol. 2020;71: 14-26. DOI: 10.1016/j.bpobgyn.2020.08.005.

61. MuhaidatN, SalehS, FramK, NabhanM,AlmahallawiN, Alryalat SA, Elfalah $M$, Elfalah $M$. Prevalence of endometriosis in women undergoing laparoscopic surgery for various gynaecological indications at a Jordanian referral centre: gaining insight into the epidemiology of an important women's health problem. BMC Women's Health. 2021;21: 381. DOI: 10.1186/s12905-021-01530-y.

62. MissmerSA, HankinsonSE, SpiegelmanD, BarbieriRL, Marshall LM, Hunter DJ. Incidence of laparoscopically confirmed endometriosis by demographic, anthropometric, and lifestyle factors. Am J Epidemiol. 2004;160(8): 784-96. DOI: 10.1093/aje/kwh275.

63. Agarwal SK, Chapron C, Giudice LC, Laufer MR, Leyland N, Missmer SA, Singh SS, Taylor HS. Clinical diagnosis of endometriosis: a call to action. Am J Obstet Gynecol. 2019;220(4): 354.e1-e12. DOI: 10.1016/j. ajog.2018.12.039.
64. Teede HJ, Misso ML, Costello MF, Dokras A, Laven J, Moran L, Piltonen T, Norman RJ. Recommendations from the international evidence-based guideline for the assessment and management of polycystic ovary syndrome. Hum Reprod. 2018;33(9): 1602-18. DOI: 10.1093/humrep/ dey256.

65. Dunselman GA, Vermeulen N, Becker C, CalhazJorge C, D'Hooghe T, De Bie B, et al. ESHRE guideline: management of women with endometriosis. Hum Reprod. 2014;29(3): 400-12. DOI: 10.1093/humrep/det457.

66. Brincat M, Galea R, Buhagiar A. Polycystic ovaries and endometriosis: a possible connection. $\mathrm{Br} \mathrm{J}$ Obstet Gynaecol. 1994;101(4): 346-8. DOI: 10.1111/j.14710528.1994.tb13625.x

67. McGovern PG, Legro RS, Myers ER, Barnhart HX, Carson SA, Diamond MP, et al. Utility of screening for other causes of infertility in women with "known" polycystic ovary syndrome. Fertil Steril. 2007;87(2): 442-4. DOI: 10.1016/j. fertnstert.2006.06.050.

68. Hager M, Wenzl R, Riesenhuber S, Marschalek J, Kuessel L, Mayrhofer D, et al. The prevalence of incidental endometriosis in women undergoing laparoscopic ovarian drilling for clomiphene-resistant polycystic ovary syndrome: a retrospective cohort study and meta-analysis. J Clin Med. 2019;8(8): 1210. DOI: 10.3390/jcm8081210.

69. Ott J, Mayerhofer K, Nouri K, Walch K, Seemann R, Kurz C. Perioperative androstenedione kinetics in women undergoing laparoscopic ovarian drilling: a prospective study. Endocrine. 2014;47(3): 936-42. DOI: 10.1007/ s12020-014-0267-1.

70. Salah IM. Office microlaparoscopic ovarian drilling (OMLOD) versus conventional laparoscopic ovarian drilling (LOD) for women with polycystic ovary syndrome. Arch Gynecol Obstet. 2013;287(2): 361-7. DOI: 10.1007/s00404012-2526-9.

71. Meuleman C, Vandenabeele B, Fieuws S, Spiessens C, Timmerman, D, D'Hooghe T. High prevalence of endometriosis in infertile women with normal ovulation and normospermic partners. Fertil Steril. 2009;92(1): 68-74. DOI: 10.1016/j.fertnstert.2008.04.056.

72. Holoch KJ, Savaris RF, Forstein DA, Miller PB, Higdon, HLee III, Likes CE, Lessey BA. Coexistence of polycystic ovary syndrome and endometriosis in women with infertility. J Endometr Pelvic Pain Disord. 2014;6(2): 78-83. DOI: 10.5301/je.5000181.

73. Janssen EB, Rijkers AC, Hoppenbrouwers K, Meuleman C, D'Hooghe TM. Prevalence of endometriosis diagnosed by laparoscopy in adolescents with dysmenorrhea or chronic pelvic pain: a systematic review. Hum Reprod Update. 2013;19(5): 570-82. DOI: 10.1093/ humupd/dmt016.

74. Kichukova D. Polycystic ovaries in association with pelvic endometriosis in infertile women diagnosed by laparoscopy. Folia Med (Plovdiv). 1996;38(3-4): 71-3.

75. Thessaloniki ESHRE/ASRM-Sponsored PCOS Consensus Workshop Group. Consensus on infertility treatment related to polycystic ovary syndrome. Fertil Steril. 2008;89(3): 505-22. DOI: 10.1016/j.fertnstert.2007.09.041.

76. Vause TD, Cheung AP. Ovulation induction in polycystic ovary syndrome. J Obstet Gynaecol Can. 2010;32(5): 495502. DOI: 10.1016/S1701-2163(16)34504-2.

77. Arumugam K, Mahmood TA, Kong YF. The association of anovulation and endometriosis in the infertile 
female. Aust N Z J Obstet Gynaecol. 1989;29(3 Pt 2): 35051. DOI: 10.1111/j.1479-828x.1989.tb01761.x.

78. Peterson CM, Johnstone EB, Hammoud AO, Stanford JB, Varner MW, Kennedy A, et al. Risk factors associated with endometriosis: importance of study population for characterizing disease in the ENDO
Study. Am J Obstet Gynecol. 2013;208(6): 451.e1-e11. DOI: 10.1016/j.ajog.2013.02.040.

79. Hemmings R, Rivard M, Olive DL, Poliquin-Fleury J, Gagné D, Hugo P, Gosselin D. Evaluation of risk factors associated with endometriosis. Fertil Steril. 2004;81(6): 1513-21. DOI: 10.1016/j.fertnstert.2003.10.038. 